\title{
ALÉM DO ASPECTO PURAMENTE ACADÊMICO: O TRABALHO DE CAMPO COMO UMA VERDADEIRA EXPERIÊNCIA DE VIDA
}

\author{
Daniel Monterio Huertas*
}

\section{RESUMO:}

O presente artigo tem como objetivo relatar a rica experiência de saída a campo em duas ocasiões recentes, quando foram percorridos cerca de 20 mil quilômetros pelas regiões Norte e CentroOeste do país. Além dos aspectos operacionais anteriores às viagens, pretendemos enfocar questões relevantes que exigem do geógrafo um olhar apurado e crítico do espaço geográfico, sempre atento às peculiaridades do lugar.

\section{PALAVRAS-CHAVE:}

espaço geográfico, paisagem, planejamento e cotidiano local

\section{ABSTRACT:}

This present paper has as objective relates the rich field research experience in two recent occasions, when had been run about 20 thousand kilometers in the North and Middle West regions. Beyond the previous operational travel's aspects, we pretend bring into focus important questions that require of the geographer a critic and refined look of the geographical space, always attentive to the local particularities.

\section{KEY WORDS:}

geographical space, landscape, planning and local daily life.

Por trás de todo trabalho de campo sempre se esconde uma infinidade de surpresas. E cabe ao geógrafo, na medida do possível, tentar captá-las e incorporá-las ao seu repertório, criando maiores possibilidades de adequar o seu objeto de estudo a uma análise mais eficaz e satisfatória. Como primeira condição necessária à saída de campo, considero de vital importância a adoção prévia de um sistema de conceitos capaz de formular - arcabouço teórico-metodológico que inegavelmente direcionará o olhar do geógrafo no campo - uma espécie de "bússola" na formulação das idéias, análises e observações, moldando o embasamento de todo o trabalho.
Pude perceber com clareza tais determinações em duas viagens recentes: uma dedelas com duração de 62 dias pelo âmago da Bacia Amazônica, no segundo semestre de 2005; e outra de 70 dias pela Amazônia meridional e partes do Centro-Oeste, no segundo semestre de 2006, privilégio e oportunidade ímpar para a pesquisa de minha dissertação. No total, foram cerca de $20 \mathrm{mil}$ quilômetros percorridos em 9 Unidades da Federação (vide figura) - dos quais 18 mil por via rodoviária e o restante pelos rios Madeira (Porto Velho - Manaus), Amazonas (Manaus Santarém) e Tapajós (Santarém - Itaituba) -, 128 cidades conhecidas e 44 entrevistas formais 
realizadas em diversos órgãos públicos, empresas privadas e sindicatos, além de inúmeras conversas informais com pessoas de todos os tipos. Mas não quero me prender a esses números grandiosos, pois eles de nada valem se não estiverem condizentes com a essência da pesquisa, fornecendo dados, informações, análises e reflexões imprescindíveis e necessárias para a elaboração do trabalho acadêmico.

A expansão da chamada fronteira agrícola, a partir da década de 1950, proporcionou uma complexidade territorial susceptível à análise geográfica, configurando um novo espaço da circulação que estreita o vínculo de fluxos entre partes do Centro-Oeste e do Norte do País. Direcionando o foco do objeto de estudo para a fluidez territorial nesses "pedaços" do território nacional, a proposta de nosso trabalho, então, parte da hipótese de que uma rede estruturadora de fluxos materiais, composta pelo entrelaçamento de vetores rodoviários e hidroviários em pontos nodais estratégicos (Manaus, Belém, Porto Velho e eixo Goiânia - DF), está se configurando para atender aos anseios da inserção e do crescimento de relevantes circuitos produtivos (principalmente soja, madeira, recursos minerais e pecuária bovina) nessas áreas, tidas até recentemente como desprovidas de movimento.

"Partimos do conceito de fluidez territorial para definir aquela qualidade dos territórios nacionais que permite uma aceleração cada vez maior dos fluxos que o estruturam, a partir da existência de uma base material formada por um conjunto de objetos concebidos, construídos e/ou acondicionados para garantir a realização do movimento. Esses fixos produtivos servem nos diferentes momentos do processo produtivo: na produção propriamente dita (stricto sensu), na distribuição, na troca, no consumo" (Arroyo, 2001:105).

Por trás da instalação do meio técnicocientífico-informacional (Santos, [1996]) meio geográfico característico do período atual, desenha-se um quadro composto por elementos relacionados ao binômio psicoesfera tecnoesfera e por um crescente processo de normatização - que tentam justificar os eventos portadores de racionalidades exógenas ao lugar. "A tecnoesfera se adapta aos mandamentos da produção e do intercâmbio e, desse modo, freqüentemente traduz interesses distantes (...). A psicoesfera, reino das idéias, crenças, paixões e lugar da produção de um sentido, também faz parte desse meio ambiente, desse entorno da vida, fornecendo regras à racionalidade ou estimulando o imaginário. Ambas (...) são locais, mas constituem o produto de uma sociedade bem mais ampla que o local" (Santos, [1996]:256).

Como preocupação analítica central, além de tentarmos justificar a configuração da rede supracitada, reside a possibilidade de que possa ocorrer uma coesão territorial que fortaleça o ainda tênue perfil do mercado nacional. Assim, cabe questionarmos de que maneira esse processo está se desenvolvendo e a quem realmente ele beneficiará.

\section{Questões Operacionais}

Quando a Geografia rompe as quatro paredes, os sistemas de objetos e ações que compõem o espaço geográfico (Santos, [1996]) tornam-se mais perceptíveis e palpáveis, embora isso não signifique que necessariamente eles se abrirão aos nossos olhos de maneira automática. Dessa forma, é interessante lançar-se ao campo com um grau mínimo de organização, permitindo que sejam construídas antecipadamente as primeiras interações com as áreas que deverão ser visitadas. Além disso, penso ser de fundamental importância possuir um conhecimento razoável sobre o objeto de estudo. Neste ponto, valem todas as fontes: além de livros, teses, dissertações e artigos acadêmicos, é importante dialogar com pessoas, independentemente de quem sejam, que conhecem ou já vivenciaram algum aspecto daquela realidade, por menor que possa ser o grau de inteligibilidade delas a 
Além do aspecto puramente acadêmico:

respeito. Pela internet, é possível acessar previamente informações locais e/ou regionais relevantes de órgãos públicos e da mídia impressa.

Ainda antes de zarpar para a pesquisa empírica, é imprescindível efetuar um planejamento eficiente, de modo a tornar a experiência no mínimo satisfatória. Deve ser muito decepcionante retornar do campo sem ter conseguido conversar com pessoas, sem ter visitado algumas instituições e até mesmo sem ter passado por lugares que inevitavelmente ampliariam o espectro analítico e o nível de compreensão da realidade a ser estudada. Para o geógrafo, certos aspectos da realidade a respeito de seu objeto de pesquisa não podem passar despercebidos.

Cerca de dois meses antes das viagens, comecei a articular as entrevistas que seriam necessárias para a pesquisa. Em todas elas, primeiramente procurei conhecer o organograma do órgão público ou da empresa que visitaria informação que geralmente está disponível nos sites institucionais - , a fim de entrar em contanto com a pessoa correta. O segundo passo incluiu um contato telefônico para solicitar a entrevista com posterior envio (eletrônico) de uma carta de apresentação assinada pela orientadora, em documento com timbre da universidade. Em empresas maiores, é recomendável entrar em contato direto com a Assessoria de Imprensa, que se responsabiliza pelo encaminhamento da solicitação e pela liberação da entrevista.

No meu caso, como não havia uma data específica de estada nas cidades, já que me encontrava em trânsito permanente, ficou estabelecida uma data aproximada, que seria confirmada assim que eu chegasse e me instalasse em algum hotel. Essa tática deu certo e fui atendido com cortesia em todos os lugares. Gostaria apenas de ressaltar que pude perceber uma sensível diferença nas empresas privadas, cujas informações, no mundo globalizado, tornam-se altamente estratégicas, principalmente as relacionadas a investimentos futuros e despesas correntes.
Além disso, a visita ao terminal graneleiro da Cargill Agrícola S/A, situado em Santarém $(P A)$, exigiu muita paciência, já que o Departamento de Marketing da matriz, por onde foi feito o contato inicial, não demonstrava boa vontade em receber um pesquisador acadêmico. Depois de muita insistência e do envio de informações mais detalhadas sobre a pesquisa em si, a entrevista foi finalmente liberada pela matriz.

De modo geral, os representantes das empresas se prendem aos dados que já estão impressos em material institucional (folder, clipping e informativo interno), fato que exige uma certa habilidade do entrevistador para romper, na medida do possível, essa barreira. Já no setor público, observei uma possibilidade de diálogo mais abrangente, com maiores possibilidades de coleta de material, embora também exista um certo sigilo em relação às informações monetárias. Caso haja anuência do entrevistado em gravar a entrevista, é interessante notar como as pessoas se portam de modo mais formal diante do gravador. Em certos momentos, ficam até mesmo reticentes em relação a algum aspecto indagado.

Antes de ir a campo, porém, também é necessário decidir o momento mais adequado para fazê-lo. Claro que essa questão depende do estágio de desenvolvimento da pesquisa, da abrangência do objeto de estudo e de outros fatores de ordem particular, mas não creio ser vantajoso fazê-lo muito adiante, e também nem no início da empreitada acadêmica. Corremos o risco de trabalhar em tempo curto, prejudicando a análise das possíveis relações do objeto de estudo com o empírico, ou, ao contrário, de não dispor de um amadurecimento mais palpável da realidade que se pretende estudar. O meu primeiro trabalho de campo foi realizado após o cumprimento das disciplinas obrigatórias e o segundo, igualmente abrangente, foi programado para ocorrer no semestre anterior ao estipulado oficialmente para o depósito da dissertação. 


\section{Observando e "Lendo" a Paisagem}

No campo, acredito que uma observação atenta e bem apurada da paisagem é a primeira etapa da análise do espaço geográfico. De acordo com a compreensão teórica de Milton Santos [1996, p.103], a paisagem, uma das categorias analíticas do espaço, "é o conjunto de formas que, num dado momento, exprime as heranças que representam as sucessivas relações localizadas entre homem e natureza". É um sistema material que se caracteriza por uma dada distribuição de formas-objetos, providas de um conteúdo técnico específico. A "leitura" da paisagem tem a capacidade de nos fornecer subsídios e elementos que conduzem ao estabelecimento de relações e variáveis intrínsecas ao objeto de estudo, proporcionando o posterior amadurecimento analítico.

Lembro-me de chegar chegar a Manaus, após três dias e meio navegando pelo Rio Madeira, meus olhos imediatamente se voltaram para a orla da cidade, tamanha a miríade de objetos distribuídos ao longo da margem esquerda do Rio Negro. Pude perceber a dimensão da Refinaria de Manaus (Reman), a quantidade de terminais fluviais privados e de estaleiros, o ferry boat de ligação com a BR 319, além de todo o movimento de ribeirinhos, ora pilotando voadeiras, ora se equilibrando em canoas. Foram informações relevantes, capazes de compor um quadro inicial de idéias e reflexões a respeito da fluidez territorial daquela realidade.

Nas viagens de ônibus, quase todas realizadas durante o dia, observei a ocupação ao longo das rodovias, a condição das estradas, o tipo e a densidade dos fluxos. Na Transamazônica, por exemplo, pude notar que os ônibus da Viação Transbrasiliana, empresa responsável pelas rotas entre Itaituba, Altamira e Marabá, possuem a carroceria mais levantada e os eixos, molas e suspensões reforçados e além disso, sempre há dois motoristas em cada carro da empresa. Todos esses fatores têm um propósito e podem ser explicados pelas circunstâncias precárias da fluidez territorial daquela região. Em Belém, há uma nítida configuração da orla em duas vertentes completamente distintas: uma relacionada ao circuito superior (terminais fluviais privados, porto organizado e pontos turísticos) e outra ao inferior (portos e mercados ribeirinhos).

Os elementos que compõem a psicoesfera que tenta justificar as formas e os conteúdos do período espalham-se pela paisagem. Na beira das rodovias, é comum encontrar placas que exaltam a chegada da modernidade, os circuitos produtivos do lugar e a reivindicação por melhorias em grandes eixos viários. Abaixo, alguns exemplos:

? $\quad$ "Bem-vindo a Aparecida do Rio Doce. Grande produtora de aves, suínos e bovinos";

? "Tecnologia que produz lucro" Fazenda São Jerônimo (Alto Garças/MT);

? "Bem-vindo a Nova Lacerda. Progresso que avança horizontes";

? "Porque a roçada pertence ao passado" - Agropecuária Campo Verde (Vilhena/ $\mathrm{RO})$;

? "Capital do boi gordo" Chupinguaia, município com o maior rebanho bovino de RO;

Canaã (MT);

? "Capital do gado e do leite" - Nova

? $\quad$ "Bem-vindos a Canarana. Capital da soja no Vale do Araguaia";

? "Um guerreiro que busca o progresso e o sucesso da região, apesar de todas as adversidades" - Homenagem ao Dia do Produtor Rural, em Santarém (Apoio: Cargill);

? "Capital do boi gordo" - Araguaína

? "Duplicação Já! BR 364/163" Campanha da Associação dos Transportadores 
Além do aspecto puramente acadêmico:

de Carga do Mato Grosso (ATC) pela duplicação do trecho entre Rondonópolis e Nova Mutum (Trevo do Lagarto, em Várzea Grande);

? "SOS BR 163. Concluir é a solução!" - Adesivos de automóveis (Realização: Sindicato Rural de Sinop, Codenorte, Famato, Aprosoja/ MT, AMPA, Apromat, Prefeitura e vereadores de Sinop.

Cabe ao geógrafo desvendar esse contexto e encaixá-lo a outros elementos do objeto de estudo, estabelecendo um esquema metodológico operacional com as demais categorias analíticas do espaço geográfico. Desse modo, a reflexão atinge um grau de interrelação e coerência condizente com a própria natureza da ciência geográfica, complexa e abrangente.

\section{Relatos do Cotidiano: uma "Mina" de Informação Local}

Mas a pura e simples observação da paisagem não basta. O trabalho de campo precisa ser instigado constantemente por um certo "mergulho" na realidade, algo que pode nos fascinar diante do desconhecido. Falar com as pessoas do lugar é interessante, onde quer que seja: no ônibus, na rodoviária, nos mercados, na fila do banco, no balcão do hotel, na banca de jornal, na padaria, no boteco. Com o ambulante, com o vendedor, com o cobrador, com o guia turístico, com a secretária. Parte do cotidiano dos lugares pode ser revelada em pequenas conversas, diálogos informais e preciosos, verdadeiras "minas de informação" que fecundam idéias, fatos, elementos, dicas. Trata-se de informações que dificilmente serão encontradas nos livros.

$\mathrm{Na}$ conversa com o armador do barco "Coração de Mãe", da rota Porto Velho Manaus, percebi como o transporte fluvial misto não está recebendo a devida atenção do poder público. O gerente da Ronav, empresa de transporte fluvial de Porto Velho, forneceu boas dicas a respeito do monopólio no setor exercido por uma grande empresa de Manaus. Na viagem entre Ribeirão Cascalheira e São Félix do Araguaia, no nordeste mato-grossense, um peão de fazenda oriundo do sertão potiguar relatou uma boa dose da realidade das fazendas do Vale do Araguaia. Na balsa sobre o Rio Juruena, no noroeste mato-grossense, um carro com a placa de São José do Rio Preto (SP) me chamou a atenção: pertencia a dois vendedores autônomos percorrendo Rondônia e o Mato Grosso em busca de potenciais compradores para os famosos bordados de Ibitinga.

Nessas áreas de "ocupação recente", é riquíssimo tentar compreender as múltiplas variáveis dos processos de colonização implantados a partir dos anos 50, sobretudo durante o governo militar. Milhares de sulistas, paulistas, mineiros, capixabas, goianos e nordestinos - pequenos, médios e grandes -, induzidos ou não, rumaram para as terras que prometiam ser o "Eldorado do século $X X^{\prime \prime}$, com muitas oportunidades de trabalho e de apropriação fundiária. Na ilusão de todos, entretanto, residia a perspectiva de se "melhorar de vida", essência que exprime os mais diversos significados e que varia de acordo com a mentalidade, renda e grau de formação das pessoas.

José Borges Bandeira, de 58 anos, trocou Teresina por Marabá em 1978 para trabalhar como carpinteiro do Instituto de Colonização e Reforma Agrária (Incra). Depois foi barrageiro em Tucuruí e encarregado de obras em Porto Trombetas. Está em Itaituba (PA), no meio do trecho paraense da Transamazônica, há 28 anos e hoje possui uma pequena propriedade rural. "Vinha muita gente de fora, com ônibus cheios, para ser escalada nas agrovilas." Cléber, de 35 anos, saiu de Corbélia (PR) aos 8 anos de idade, rumo a Lucas do Rio Verde (MT), mas há três anos vive em Moraes de Almeida (PA), nas margens da Cuiabá-Santarém. Iria encarar cerca de 320 quilômetros de terra no ônibus da empresa Satélite Norte desde Itaituba, onde estivera para comprar insumos agrícolas. "Meu pai diz que sempre está fugindo do asfalto." 
Rosto cansado, seu Francisco fala com orgulho do longínquo 10 de fevereiro de 1970, dia exato que desembarcou em Cacoal (RO), depois de 22 dias de viagem de caminhão desde Goio-Erê (PR). "Foi a pior viagem da minha vida. Tivemos de abrir picadas no Mato Grosso com foice e facão." Quando chegou, Cacoal era um "punhado de casas de madeira rodeadas de borracha, índio e mato", mas havia a perspectiva de crescer. Hoje, aos 51 anos, vive de subsistência em 200 alqueires na zona rural de Pimenta Bueno em situação difícil e com os filhos "espalhados pelo mundo". "Esperávamos mudar de vida, mas estamos na mesma. Entra aí nesse mato para você ver se é bom...", diz.

Moacir Paulino de Azevedo, 57 anos, paranaense de Marechal Cândido Rondon, chegou a Cuiabá em 1977 e, desde 1999, vive em Colíder, no chamado "Nortão do Mato Grosso". À bordo do Golfinho do Mar, barco da rota Manaus - Santarém, regressava de Alto Alegre (RR), onde havia feito uma análise de mercado para a venda de bombas injetoras de óleo diesel. É favorável ao desmatamento da Amazônia por questões econômicas. "Passei toda a minha infância vendo as araucárias indo para as serrarias. Se não fosse assim, o Paraná não seria o que é hoje."

Em fevereiro de 1982, com 25 anos de idade, Hamilton de Oliveira embarcou em Guaíra (PR) em um ônibus da União Cascavel com destino a Ji-Paraná (RO) para trabalhar no asfaltamento da BR 364, obra incluída no Programa Integrado de Desenvolvimento do Noroeste do Brasil (Polonoroeste). "Naquela época, a gente vendia 2, 3 alqueires no Paraná, comprava 40 alqueires aqui e ainda ganhava mais 40 alqueires do Incra." Atualmente, é funcionário de carreira da prefeitura local.

A família Maggi, oriunda do Rio Grande do Sul, orgulha-se do fato de ter constituído um dos maiores impérios do agronegócio do País, o Grupo Maggi. Em autêntico estilo self-made man norte-americano, a empresa recentemente lançou um cd ("A saga de um bandeirante no coração do cerrado") para homenagear e contar a trajetória de seu fundador, André Maggi, morto em 2002. Pai do atual governador do Mato Grosso, Blairo Maggi, ele seguiu a "rota gaúcha" adquirindo propriedades no oeste paranaense para posteriormente se lançar em Itiquira, no sul do Mato Grosso, onde chegou em 1979. Também há uma psicoesfera preparada para enaltecer esses casos de pioneirismo que se transformaram em grandes empresas.

Além dos relatos pessoais, dar uma espiada nos jornais e telejornais locais também constitui uma boa fonte de informação, embora a análise midiática sempre exija um olhar mais crítico de nossa parte. Nesse aspecto, eu tive um pouco de sorte, pois o objeto de estudo de minha pesquisa também estava sendo bastante debatido e analisado pela imprensa dos Estados visitados. A recuperação da BR 319 (Porto Velho - Manaus), o imbróglio jurídico pelo qual está sendo submetido o porto organizado de Manaus, o escoamento da soja pelo terminal da Cargill em Santarém, a construção de um novo terminal marítimo de exportação de minério de ferro no Pará (aliança entre a Companhia Vale do Rio Doce/CVRD e a Companhia Docas do Pará/CDP) e o asfaltamento da CuiabáSantarém renderam numerosos artigos jornalísticos na impressa local, com dados que podem e devem ser utilizados.

\section{Periodização: um Caminho de Método}

Quando observou e analisou a marcha do café pelo Oeste Paulista e norte do Paraná, em meados da década de 1940, o então jovem geógrafo Pierre Monbeig [1950] lançou mão de dois artifícios interessantes em suas pesquisas: as conjunturas fortuitas e a conjuntura mundial, que juntas constituem um arcabouço analítico imprescindível à compreensão geográfica, do qual preferiu chamar de circunstâncias históricas. Essa ferramenta torna-se relevante para a formulação da periodização de nosso objeto de estudo, pois nos mostra quais foram os elementos responsáveis pela ruptura do período e quais são os objetos e as ações condizentes com o atual período, o técnico- 
Além do aspecto puramente acadêmico:

científico-informacional (Santos, [1996]).

No caso da minha pesquisa, questioneime como compreender a atual conjuntura da fluidez territorial do Centro-Oeste em direção à Amazônia sem o estudo dos elementos históricos que acionaram o movimento de progressão de marchas pioneiras a partir do Governo JK. E como analisar o processo de expansão da chamada fronteira agrícola, sem inserir os desígnios propostos pela Revolução Verde à realidade brasileira?

Nesse sentido, acreditamos que a constituição das redes técnicas deve ser analisada mediante uma periodização condizente com as transformações do meio geográfico. O incremento técnico e normativo imposto aos modais de transporte desde o ciclo da borracha, quando embarcações de grande porte com propulsão mecânica foram introduzidas na Bacia Amazônia e nos rios Cuiabá e Paraguai, até o período atual acaba sendo um dos elementos-chave dos períodos da logística na área de estudo. As mudanças estruturais relacionadas ao binômio tecnoesfera - psicoesfera e os arranjos territoriais decorrentes de todo o processo também foram analisados.

\section{Palavras Finais}

Jamais podemos nos esquecer das particularidades do espaço geográfico latinoamericano, e o entendimento das circunstâncias históricas, proposto por Monbeig, são excelentes elos para a compreensão daquilo que Milton Santos (1978) chamou de espaço derivado, com as suas respectivas variáveis específicas dos países subdesenvolvidos.

O trabalho de campo contempla inúmeros aspectos que precisam ser submetidos a um intenso processo de interrelação, sempre objetivando chegar o mais próximo possível da realidade, ou melhor, da totalidade de nosso objeto de estudo. Um trabalho que, após a adoção de uma orientação teórico-metodológica, certamente exigirá um cansativo e extenuante "mergulho profundo" na realidade a ser analisada. Além dos elementos puramente acadêmicos, sugiro que o geógrafo tente decifrar a força e a energia dos lugares como algo que extrapole a dimensão fisiológica de seu sistema sensorial. Dessa forma, o trabalho de campo deixa de ser apenas acadêmico, transformandose também em uma verdadeira experiência de vida.

\section{Bibliografia}

ARROYO, Maria Mónica. Território nacional e mercado externo: uma leitura do Brasil na virada do século XX. Tese de doutorado, Departamento de Geografia (DG/FFLCH/USP), São Paulo, 2001, 250p.

MONBEIG, Pierre. [1950] Pioneiros e fazendeiros de São Paulo. São Paulo: Hucitec, 1998, 392p.
SANTOS, Milton. O trabalho do geógrafo no Terceiro Mundo. São Paulo: Hucitec, 1978, 113p. - [1996] A natureza do espaço: técnica e tempo, razão e emoção. $4^{a}$ ed. São Paulo: Edusp, 2004, 384p.

Artigo enviado em fevereiro de 2007 


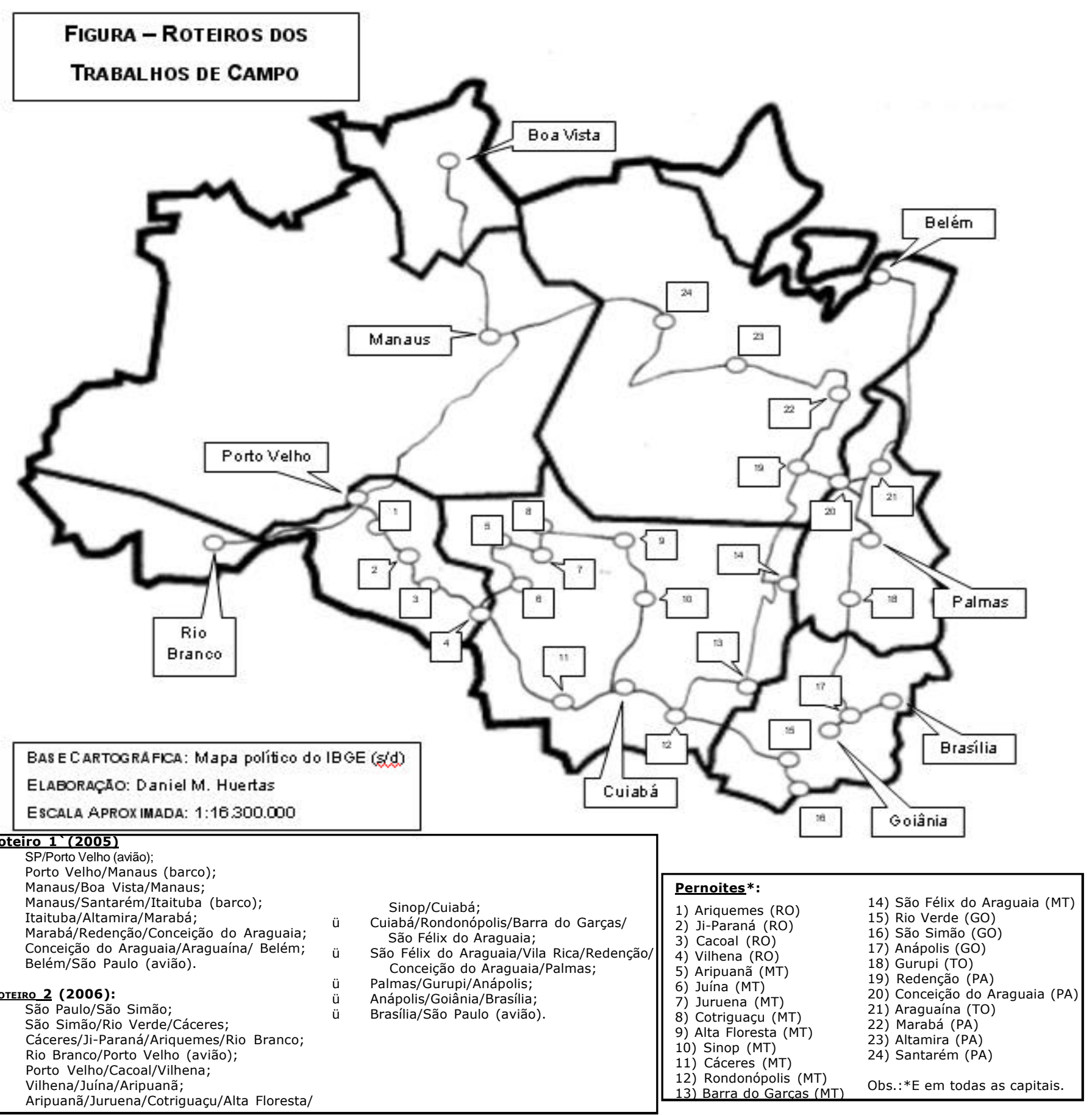


